\title{
Recent Changes in Taiwan Animal Testing Laws
}

August 22, 2015

Ting,

Master of Laws Candidate, Hitotsubashi University

Moe Honjo,

Doctoral Candidate, Hitotsubashi University

1. Introduction

2. Bill of Cosmetic Animal Testing Ban

(2-1) Current Situation regarding Cosmetic Animal Testing

(2-2) Overview of the amendments to Taiwan's Control for Cosmetic Hygiene Act

(2-3) Documents of May 14, 2014

(a) Legislative Intent

(b) Contents of the Proposal

(2-4) Amendment of the Bill

3. Regulation for Establishing and Management of The Animal Care and Usage Committee/Panel

(3-1) Overview of changes made in Regulation for Establishing and Management of The Animal Care and Usage Committee/Panel

(3-2) Full Text of (unofficial) English Translation of the Amendment

(3-3) Notable Changes made in the Amendment
(a) Changes in Name of the Regulation
(b) Changes in Article 2
(c) Changes in Administrative (Management) Authority
(d) Changes in Article 3

4. Conclusion 


\section{Introduction}

Responding to significant changes in consumers' demand and concern regarding safety of chemicals and protection of animal, cosmetic regulation has been amended all over the world. One of the significant global trend of amendments is regulation regarding animal testing for cosmetics (hereafter cosmetic animal testing) and Taiwan is not an exception. ${ }^{1}$

This report does not provide a big picture of animal testing law in Taiwan, but only provides information regarding some sign of changes in Taiwan regarding animal testing regulation. Taiwan introduced a bill to ban animal testing of cosmetics in 2014, and several regulations has been amended to protect laboratory animals in general. According to Professor. Li of National Taipei University who devoted himself into development of Taiwan animal law, the enforcement issue remains to realize animal protection in Taiwan. However, this report explains what changes we can witness from wording of law as the attempt of making improvement is worth noting.

Part 2 analyzes a bill to ban cosmetic animal testing. In part 3, Ting translates the 2013 revision of Regulation for Establishing and Management of The Animal Care

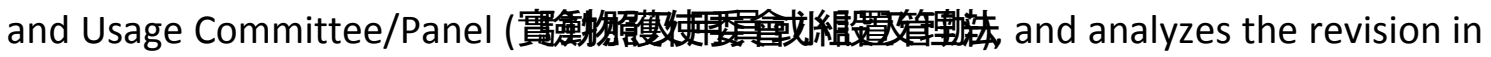
part 4. Part 5 concludes this report.

\footnotetext{
${ }^{1}$ Definition of "Cosmetics" under Taiwan law.

Article 3 of Statute for Control of Cosmetic Hygiene, "The term "cosmetic(s)" as used in this Statute shall refer to the substance(s) for external use on human body in order to freshen the hair or skin, to stimulate the sense of smell, to cover body odor, or to improve facial appearance. The scope and categories of cosmetics shall be defined as per public notice(s) to be published by the central competent health authorities."

http://law.moj.gov.tw/Eng/LawClass/LawAll.aspx?PCode=L0030013
} 


\section{Bill of Cosmetic Animal Testing Ban}

Cosmetic animal testing regulation may change soon in Taiwan. Since 2014, a bill to amend Taiwan's Control for Cosmetic Hygiene Act has been under consideration. If it passes, it bans cosmetic animal testing and harmonizes with the EU cosmetic animal testing ban in some extent. After briefly explains the current situation of cosmetic animal testing requirement in Taiwan, this chapter analyzes the legislative intent and the overview of the bill.

\section{(2-1) Current Situation regarding Cosmetic Animal Testing}

Taiwan currently does not ban cosmetic animal testing. Rather, Taiwan government requires cosmetic animal testing in limited case. Control of Cosmetic Hygiene Act provides general definitions and requires licensing of manufacturer and importers of cosmetic products. There are two types of cosmetic products in Taiwan. First type of cosmetics is containing medical, poisonous or potent drug(s). Sunscreen, hair dye, and tooth whitening are often categorized in this type. Second type is ordinary cosmetics including make-up and fragrances. To sell the second type of cosmetics, institutions do not have to conduct animal testing. However, if institutions attempt to use new chemicals to make the first type of cosmetics, one has to conduct animal testing. However, FDA (Food and Drug Administration) of Taiwan can state some exceptions of the requirement of animal testing, ${ }^{2}$ and FDA tends to shift to the EU way of regulating chemicals, with amount of usage. ${ }^{3}$

The idea of cosmetic animal testing ban was introduced to the bill of Control for Cosmetic Hygiene Act instead of Animal Protection Act. The likely reason is that it would be too early or too tough to include various animal experiment fields into strict

\footnotetext{
2 Food and Drug Administration, http://www.fda.gov.tw/TC/siteListContent.aspx?sid=1152\&id=1034\&chk=13528626-60e3-4f07-9caf391c0c76f415\&param=pn\%3d1\%26sid\%3d1152\#.Vv4fH3B387C ((Last viewed on April 1, 2016)

3 Food and Drug Administration, http://www.fda.gov.tw/TC/siteList.aspx?sid=1152 (Last viewed on April 1, 2016)
} 
regulation (such as ban), and it would be more realistic to introduce animal testing ban only in the cosmetic field.

(2-2) Overview of the amendments to Taiwan's Control for Cosmetic Hygiene Act

The bill was read out loud in the Yan Sitting (First Reading) on May $14^{\text {th }} 2014$, and it has been amended overtime. Amendment of Clause 2 of Article 23 and Article 27 regarding animal testing is being considered. The most recent amendment of the bill was made on March $2^{\text {nd }} 2016$, and it bans marketing of cosmetics that has been tested on animals (hereafter animal tested cosmetics). This section explains the development of arguments made in Legislative Yuan. ${ }^{4}$

(2-3) Documents of May 14, 2014

(a) Legislative Intent

Official documents formally presented to the Taiwan Parliament (Legislative Yuan) in May 2014 states several reasons for introducing the bill regarding animal testing ban. ${ }^{5}$ The first reason mentioned is immorality of animal testing. According to the document, it is mentioned that animal testing does not ensure safety of cosmetic products for human use, and alternative methods are more reliable and economical than animal testing. Furthermore, the bill was introduced in the scope of total ban of animal testing in certain time period to enhance international honor and animal protection. The document explains the process how the EU has banned cosmetic animal testing, and it illustrates how the person who drafted the proposal was inspired by Cosmetic Regulation in the EU.

(b) Contents of the Proposal

\footnotetext{
${ }^{4}$ The Legislative Yuan of Republic of China, http://www.ly.gov.tw

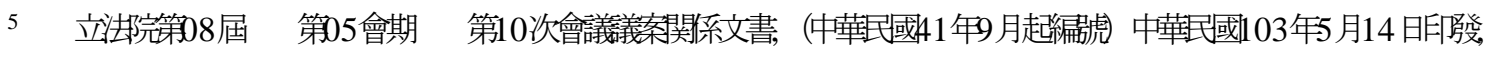
院總第874號＼cjkstart委員提案第16439號
} 
Proposal of Clause 2 of Article 23 states "If there are alternative methods, one should not conduct animal testing for safety of finished, semi-manufactured cosmetic products or ingredients of cosmetics." ${ }^{6}$ Thus, at this stage, the bill banned cosmetic animal testing only when there were alternatives. On the other hand, cosmetic animal testing ban in the EU did not have this kind of exemption, and so the law urged development of alternatives. In addition, the bill did not either ban marketing of imported cosmetic products that had been tested on animals.

Under proposed Article 27, violator of Article 23 could be liable to the penalties of a period in maximum of one year imprisonment and, or fines of not more than NT\$(New Taiwan Dollar) 150,000. In addition, where the violator is a factory, "whether a juristic person or a non-juristic person, the doer and the said juristic person or the responsible person shall both be imposed the fine." ${ }^{\prime 7}$

(2-4) Process of Discussions regarding the Bill

Document of September 10, 2014 deleted the condition that cosmetic animal testing is banned only "when non-animal used alternative methods are available." Instead, the amended version requires to end cosmetic animal testing unless human health problem occurs and animal testing is necessary. ${ }^{8}$

The amendment of proposal of March 2, 2016 bans marketing of animal tested cosmetics as follows. ${ }^{9}$

Clause 2 of Article 23 (proposal)

\footnotetext{
6 Control for Cosmetic Hygiene Act, Clause 2 of Article 23,

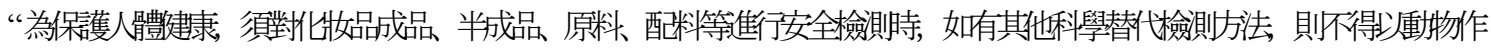
為檢賏對像。”

${ }^{7}$ Control for Cosmetic Hygiene Act, Announced on December 28, 1972, Amended on June 12, 2002, Ministry of Health and Welfare, http://law.moj.gov.tw/Eng/LawClass/LawAll.aspx?PCode=L0030013

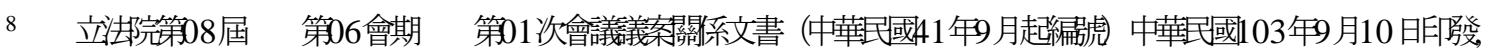
院息第8 74 號委員提案第16932號

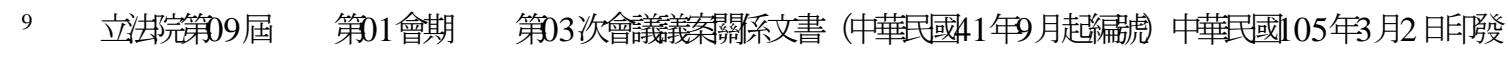
院總第874號委員提案第 18401 號
} 
"Either imported or manufactured, cosmetic ingredients, components, colorants, sample or cosmetic products made either inside the country or not, if tested on animals, shall not be provided for sale, supply or display with intent to sell."

According to the minute of meeting on March 4, 2016 held by the Legislative Yuan, the proposal has been passed to Social Welfare and Environmental Hygiene Committee for consideration. ${ }^{10}$

3. Regulation for Establishing and Management of The Animal Care and Usage Committee/Panel

The attempt of protecting laboratory animals can be seen not only in the bill discussed above, but also in the regulation that mandate animal testing institutions to make management group of laboratory animals. The revised regulation strengthened the responsibility of the management group, and made changes in administrative authority in order to manage animal testing in Taiwan properly.

(3-1) Overview of changes made in Regulation for Establishing and Management of The Animal Care and Usage Committee/Panel

Regulation for Establishing the Management Group of Animal Experiment was made in the requirement of Article 16 of the Animal Protection Act. ${ }^{11}$ According to Article 16 of the Animal Protection Act, any institution which wants to conduct animal testing has to make management group of animal experiment. Also, Article 2 of Regulation for Establishing the Management Group of Animal Experiments requires the institution has to submit member lists of the management group to the Council of Agriculture. Animal experiment conductor has to send the form of animal experiment

\footnotetext{
10 立法院公報第105 卷第3 期院會紀錄 院會紀錄 立法完第9 屆第1 會期第3 次會議限淥

${ }^{11}$ Article 1, Regulation for Establishing the Management Group of Animal Experiments
} 
to the management group of its organization, but does not need to send the data to the Council of Agriculture. ${ }^{12}$

(3-2) Full Text of (unofficial) English Translation of the Amendment

This translation of 2013 amendment is based on the official translation of the regulation. ${ }^{13}$ Gray letters show sentences that have not been changed, and blue letters show sentences that wording has been changed. At last, orange letters show sentences or words that have been added.

Regulation for Establishment and Management of Committee/Group for Laboratory Animal Care and Usage

\section{Article 1 :}

These regulations are enacted according to the provision in Paragraph 3 of Article 16 of the animal Protection Act Kereafter referred to as this Act/ APC).

\section{Article 2 :}

The institution using animals for scientific application shall set up a panel for the care and use of laboratory animals. The group is composed from three to fifteen members. The group should have veterinarians or experts ${ }^{14}$ who has passed the training course of animal experiment by the central competent authority or the commissioned training institution.

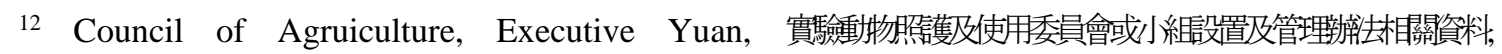
http://www.coa.gov.tw/view.php?catid=8564 (Last viewed on April 1, 2016)

${ }^{13}$ Council of Agriculture, Executive Yuan R.O.C.(Taiwan), Regulation for Establishing The Management Group of Animal Experiments, http://eng.coa.gov.tw/content_view.php?catid=8993\&hot_new=8869 
The veterinarians or the experts in preceding paragraph should participate animal management training held by the central competent authority and acquire certificates at least once every three years so that they could be members of the management group for animal experiment continually.

The institution who performs the scientific application of animals shall register and submit the member name list of the management group to competent authorities of special municipalities, counties or cities in 30 days after being approved. Changing of the group member shall follow the same procedure.

The management group of animal experiment which has animal house in different administrative division should also inform the competent authorities of special municipalities, counties or cities in which the animal house is when the group is set up or changed.

Article 3 :

The missions for the management group are as follow:

1. Examine the scientific application of animal experiment of the institution.

2. Provide the scientific application suggestion and training plans on the animal experiment design for institution.

3. Provide the suggestions of improving feeding facilities of laboratory animal for institution.

4. Supervise the institution to receive, feed, manage and apply the laboratory animal.

5. Provide the institution annual supervision report of the scientific application of animal experiment. Annual execution report shall submit to the central competent authority within three month after the end of the year.

6. Internal check should be implemented once every six months, and the results should be annexed to the oversight report and held more than six years for future reference. 
7. The institution where apes and monkeys, dogs, cats are used for scientific applications should annex the copy of the application form to the oversight report.

8. Receive the report of the controversial case which violates this regulation, and report it to the central competent authority for future reference within three months after the end of a year by the Annual oversight report in the preceding paragraph. Also inform the competent authorities in special municipalities, counties or cities which it belongs.

The items of internal check in Clause 6 of Article 3 are as follow:

1. Software check: including institution policies and duties, animal health and cure, and the management of animal feeding.

2. Hardware check: including the area of feeding and supplying, instruments and equipment, and animal surgery or experimental sites.

Article 4 :

The applicant for the scientific application of animal experiment requires applying to the management group of animal experiment. The application shall include program name, program host, animal species, variety, quantity, experimental design, implementation period, responsible for the relevant roster of animal experiments and the materials which is according to Clause 1 of Article 15 in APC about alternative methods, reduction and refinement of the assessment notes, etc.

The experiment cannot be proceeded before the group has proved.

Article 5 :

If the management group of scientific application of animal experiment finds out the researcher who violates this regulation, shall order the researcher to make improvement within a certain time. If exceed improvement certain time to make improvement, the group shall cease the animal experiment. 
Article 6 :

The institution which does not set up a panel for the care and use of lab animals should improve within a certain time. If not improved in the certain time, penalties are imposed according to Section 3 of Article 29 in APC.

The Animal Care and Use Management Group which does not carry out its duties in Section 1 of Article 3 should impose penalties according to Article 24 in APC by the competent authorities of special municipalities, counties or cities.

Article 7 :

These Regulations take effect on the day of promulgation.

(3-3) Notable Changes made in the Amendment

There are at least four notable changes in the amendment of the regulation in 2013, and details are as follows. ${ }^{15}$

(a) Changes in Name of the Regulation

Since its establishment in 2001, Chinese name of the regulation was "Regulation for Establishing The Management Group of Animal Experiments "

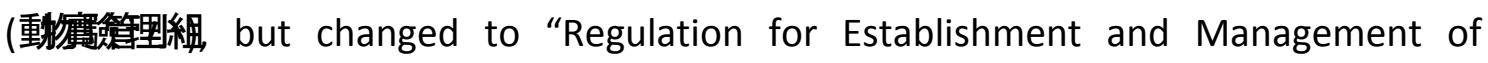

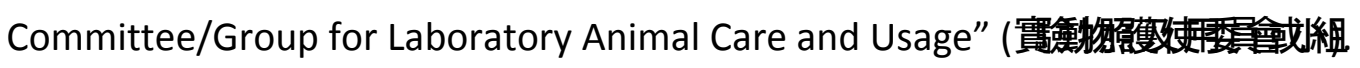

(b) Changes in Article 2

The amended regulation added detailed qualifications of panel members as veterinaries or experts. To be a member of the panel, being veterinary is not enough, but one has to be trained and acquire certificates at least once every three years.

(c) Changes in Administrative (Management) Authority

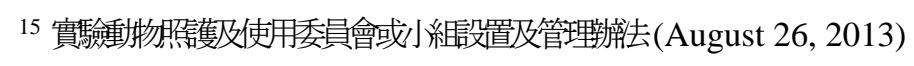




\section{dA derecho ANIMAL la web center de los animales con derecho}

Before the amendment, central government had a responsibility to control organizations of animal testing. In order to grasp the present situation, the amendment passed the administrative authority to local government, the competent authority of special municipalities, counties or cites. The management group of laboratory animals has to report to the competent authority of special municipalities, counties or cites, and approved report is registered in the competent authority at the central level. If the place of group managing laboratory animals and the place of laboratory animals are kept in different counties, reports should be sent to both counties.

(d) Changes in Article 3

Evaluation reports of each animal testing institution have to be kept for more than six years.

\section{Conclusion}

The analysis on the development of the bill regarding cosmetic animal testing ban and the evaluation on the changes made in the responsibility of animal testing management group shows the sign of changes in Taiwan for better laboratory animal protection.

While more and more countries and regions started to open the dialogue regarding animal testing, this report aimed to illustrate Taiwan is one of those. Protection of laboratory animals would not be realized without enforcement, and question on how efficient these bill or regulation are reflected in real life still remains. 